\title{
Fiziksel Tedavi Yöntemleri B. Kimyasal Peeling
}

\section{Doç. Dr. Hamdi Özcan}

Bașkent Üniversitesi Tıp Fakültesi, Zübeyde Hanım Uygulama ve Araștırma Merkezi, İzmir, Türkiye

Öz

Kimyasal peeling uygulamaları sıklıkla deri gençleştirme ve estetik amaçı yaygın olarak kullanılmakla birlikte akne lezyonlarının ve skarlarının tedavisinde de kullanılmaktadır. Aktif akne lezyonlarının tedavisinde daha çok yüzeysel peeling, skar tedavisinde ise orta ve derin peeling yöntemleri kullanılmaktadır. Kontrollü ve bilinçli kullanıldıklarında yan etkiler belirgin oranda azalmaktadır. Kimyasal peeling akne tedavisinde medikal tedavi yöntemleri, cerrahi yöntemler hatta lazer tedavisi ile kombine kullanılabilirler ve bu şekilde etkinlikleri artırıabilir.

Anahtar Kelimeler: Akne vulgaris, akne skarları, kimyasal peeling

\section{Abstract}

Although chemical peeling is used more widely for skin rejuvenation and aesthetic purposes, it is also used for the treatment of acne lesions and scars. Superficial peeling is used more for the treatment of active acne lesions, whereas medium and deep peeling for treating scars. Their side effects can be considerably reduced if used in a controlled and knowledgeable manner. In acne treatment, chemical peeling may be used in combination with medical therapies, surgical methods and even laser therapy, which can increase their overall efficacy.

Keywords: Acne vulgaris, acne scars, chemical peeling

\section{Giriş}

- Kimyasal peeling sıklıkla deri gençleştirme ve estetik amaçla uygulanan derinin yenilenmesi işlemidir ${ }^{1}$. Uygulanan kimyasal ajan deride epidermisin yüzeysel tabakası, epidermisin tamamı veya dermisi de içine alacak şekilde kontrolü doku hasarlanmasına neden olur. Uygulama sonrası deride soyulma, sonrasında yeni epidermal ve dermal doku gelişir².

- Kimyasal peelingler için ileri sürülen etki mekanizması etki derinliği ile orantılıdır ${ }^{3}$. Kimyasal peeling ajanı ile deride kontrollü olarak oluşturulan hasar sadece epidermiste ise yüzeyel, dermisin bir kısmını içine alıyorsa orta veya derin kimyasal peeling olarak adlandırıır.
- Kimyasal peeling medikal tedaviye destekleyici olarak aktif akne tedavisinde, iyileşme elde edilip yüz temizlendikten sonra idame tedavide ve akne skarlarının tedavisinde kullanılabilmektedir ${ }^{3}$.

Kimyasal peeling amacı ile en sık kullanılan maddeler aşağıda yer almaktadır.
1. Salisilik asit (SA)
2. Glikolik asit (GA)
3. Pirüvik asit (PA)
4. Laktik asit (LA)
5. Mandelik asit (MA)
6. Jessner solüsyonu (JS)

Yazıșma Adresi/Address for Correspondence: Doç. Dr. Hamdi Özcan

Başkent Üniversitesi Tip Fakültesi, Zübeyde Hanım Uygulama ve Araştırma Merkezi, İzmir, Türkiye

E-posta: drhozcan@gmail.com ORCID: orcid.org/0000-0002-9017-0358

(C)Telif Hakkı 2020 Deri ve Zührevi Hastalıklar Derneği

Türkderm - Türk Deri Hastalıkları ve Frengi Arșivi, Galenos Yayınevi tarafından basılmıștı. 
7. Triklorasetik asit (TCA)

8. Fenol

- Peeling ajanları kombine kullanıldığı zaman komplikasyon riskini azaltmakta ve daha iyi klinik sonuçlar elde edilmektedir4

- Bu ajanlar aktif akne ve akne skarlarında sebum salgısını azaltır, komedolitik etki gösterir, keratolizise neden olur, anti-enflamatuvar ve antibakteriyel etki gösterirler (Tablo 1) ${ }^{4}$.

- Aktif aknede kullanılan topikal ajanın etkisini artıracağı için klasik tedavilere ek olarak ve idame tedavide kullanılabilirler.

- Akne skarlarında diğer cilt yenileme yöntemleri ile kombine edilebilirler ${ }^{4}$

Günümüzde akne tedavisinde kimyasal peeling uygulamaları konusunda ciddi kanıt oluşturacak çalışma sayısı sınırlıdır. Hafif ve orta şiddetli akne tedavisinde yüzeyel kimyasal peeling uygulamasının sayısının artması ile etkinin daha belirgin olduğu bildirilmektedir. Enflamatuvar ve non-enflamatuvar lezyonların her ikisinde de iyileşme bildirilirken nodülokistik lezyonlarda etki minimaldir³. Dréno ve ark. $^{3}$ tarafından yapılan kanıta dayalı öneriler çalışmasında SA kullanılan altı araştırma değerlendirilmiştir. Bu çalışmalarda SA \%20-30 konsantrasyonda kullanılmış, tüm çalışmalarda hem enflamatuvar hem de non-enflamatuvar lezyonlarda etkili bulunmuştur³. Polietilen glikon sıvağ içinde \%30 SA peeling uygulamasının 436 akne hastasında ağrı, eritem, kanama, krut veya postenflamatuvar hiperpigmentasyon (PIH) gelişimine neden olmadığı ve etkin bir tedavi sağladığı bildirilmiştir ${ }^{5}$. \%20 SA ve \%10 MA kombinasyonu, \%35 GA peeling uygulaması ile karşılaştırılmıs, kombine tedavi daha etkin bulunmuştur ${ }^{3}$. Aynı çalışmada GA kullanılan dört araştırma değerlendirilmiştir. GA \%30-70 konsantrasyonda kullanılmıştır. Uygulama sayısının artması ile etkinin arttığı, komedonların enflamatuvar lezyonlara göre çok daha erken yanıt verdiği bildirilmiştir ${ }^{3}$

- Aktif akne vulgaris tedavisinde yüzeyel kimyasal peeling uygulaması etkinliğini değerlendiren bir derlemede GA (\%30-70) ve SA'nın (\%30) enflamatuvar akne lezyonlarını azaltmada etkin olduğu, GA uygulamasının deri rengi koyu olan akne hastalarında, hatta akne skarları için de kullanılabileceği sonucuna varmışlardır. Ayrıca SA ile peeling uygulamasının hiperpigmentasyonu olan koyu derili hastalarda beyazlatıc etkisi nedeni ile uygun olduğu, komedon ve papüllerde GA'ya göre daha iyi etki ettiğini vurgulamışlardır.

- Çeşitli kimyasal peeling ajanlarının akne tiplerinde etkinliği Tablo 2'de gösterilmiştir.

- TCA, kimyasal peeling için altın standart olarak kabul edilmektedir. Uygulanan konsantrasyona bağlı olarak yüzeysel, orta-derinlikte ve derin peeling etkisi gösterir. Akne skarlarının tedavisinde en etkin ajandır, ancak deri tipi koyu olan bireylerde hiperpigmentasyon riski yüksek olduğu için kullanılmamalıdır

- TCA'nın sadece akne skarlarında lezyon üzerine uygulandığı "Chemical Reconstruction of Skin Scars" tekniği yakın zamanda tanımlanan bir uygulamadır ${ }^{4}$.Yüksek konsantrasyonda (\%50-100) TCA kürdan ile özellikle buz kıracağı şeklindeki atrofik skarlarda skar yapısının taban kısmına beyaz frosting görünene kadar birkaç saniye uygulanır. Uygulama 4 hafta aralıklarla yapılır ve başarılı sonuçlar elde edilir ${ }^{4}$. Buz kıracağı atrofik skarların yanı sıra küçük keskin, dik, sınırlı, yük vagonu şeklindeki skar yapılarının tedavisi için uygun tedavi yöntemidir. İki-4 hafta aralarla 2-3 seans uygulanır ${ }^{1,7}$.

Öneri: Aktif akne lezyonlarının tedavisinde yüzeysel kimyasal peeling uygulamaları aknenin medikal tedavisine ek olarak dikkatli şekilde uygulanabilir. Akne skarlarının tedavisinde ise kimyasal peeling kişinin deri yapısı, akne skarlarının şiddeti, hastanın tedaviye uyumu ve işten kalma süreci göz önüne alınarak uygulanabilir.

- PIH tedavisinde kimyasal peelingler, lazerler ve diğer ışık tedavileri kullanılabilir, ancak bu yöntemler de pigmentasyona neden olabileceğinden dikkatli uygulanmalıdır ${ }^{8}$. SA peeling ve retinoid kombinasyonu PIH tedavisinde tedavi yöntemlerinin tek başına kullanılmasına göre daha iyi etki göstermiş, iyi tolere edilmiş ve rekürrens oranı daha düşük bildirilmiştir ${ }^{8}$. Önemli olan PIH lezyonlarının zaman içinde geçeceği konusunda hastaları bilinçlendirmek olacaktır. Tablo 3’te kimyasal peelinglerin komplikasyonları gösterilmektedir .

Tablo 1. Çeşitli peeling ajanlarının aknede etki mekanizmaları

\begin{tabular}{|l|l|l|l|l|l|l|l|l|l|}
\hline & GA & MA & LA & JS & SA & PA & TCA & Fenol \\
\hline Deskuamasyon & + & + & + & + & + & + & + & + \\
\hline Komedolizis & & & & & + & & + & + & \\
\hline Sebum üretiminde azalma & & & & + & + & + & \\
\hline Antibakteriyel etki & + & + & + & + & + & + & + \\
\hline Antienflamatuvar etki & + & + & + & & + & & + & + \\
\hline Yeni kolajen sentezi & + & + & + & + & + & + & + \\
\hline GA: Glikolik asit, MA: Mandelik asit, LA: Laktik asit, JS: Jessner solüsyonu, SA: Salisilik asit, PA: Pirüvik asit, TCA: Triklorasetik asit & & \\
\hline
\end{tabular}

Tablo 2. Çeşitli kimyasal peeling ajanlarının farklı akne tiplerinde etkinliği

\begin{tabular}{|c|c|c|c|c|c|c|c|c|}
\hline & GA & MA & LA & JS & SA & PA & TCA & Fenol \\
\hline Papülo-püstüler & + & + & + & + & + & + & + & - \\
\hline Akne skarları & + & + & + & + & + & + & + & + \\
\hline Akneye yatkın yağlı deri & + & + & - & + & + & + & - & - \\
\hline
\end{tabular}




\section{Tablo 3: Kimyasal peeling uygulamalarına bağlı} görülen komplikasyonlar ${ }^{9}$

\begin{tabular}{|l|l|l|}
\hline Ödem & Ağrı & Yanma hissi \\
\hline Sebat eden eritem & Alerjik reaksiyon & Bül oluşumu \\
\hline Folikülit & Akne & $\begin{array}{l}\text { Bakteriyel, kandidal ve } \\
\text { herpes enfeksiyonu }\end{array}$ \\
\hline Ekimoz & Hipopigmentasyon & Hiperpigmentasyon \\
\hline Telenjiektazi & Milia & Skar oluşumu \\
\hline
\end{tabular}

\section{Sonuçlar}

Yüzeysel kimyasal peeling uygulamaları akne tedavisi için güvenilir yöntemlerdir. Akne tedavisinde kullanılan ilaçlarla kombine edilebilmesi kimyasal peeling uygulamalarını daha etkili hale getirmektedir ve non-enflamatuvar ve enflamatuvar akne tedavisinde kullanılabilir 10,11. Kimyasal peeling uygulamaları sadece yüze değil, göğüs ve sırt bölgesine de uygulanabilir ${ }^{10}$. Akne skarlarının tedavisinde yine ilaçlar, cerrahi uygulamalar ve lazer tedavileri ile kombine olarak kullanılabilirler ${ }^{10,11}$.

\section{Kaynaklar}

1. Chen X, Wang S, Yang M, Li L: Chemical peels for acne vulgaris: a systematic review of randomised controlled trials. BMJ Open. 2018;8:e019607.

2. Peri S, Bubanj M, Bubanj S, Jan i S: Side effects assessment in glicolyc acid peelings in patients with acne type I. Bosn J Basic Med Sci. 2011;11:52-7.
3. Dréno $B$, Fischer TC, Perosino E, et. al: Expert opinion: efficacy of superficial chemical peels in active acne management- what can we learn from the literature today? Evidence-based recommendations. J Eur Acad Dermatol Venereol. 2011;25:695-704.

4. Kontochristopoulos G, Platsidaki E: Chemical peels in active acne and acne scars. Clin Dermatol. 2017;35:179-82.

5. Dainichi T, Ueda S, Imayama S, Furue M: Excellent clinical results with a new preparation for chemical peeling in acne: $30 \%$ salicylicacid in polyethyleneglycol vehicle. Dermatol Surg. 2008;34:891-9.

6. Al-Talib H, Al-Khateeb A, Hameed A, Murugaiah C: Efficacy and safety of superficial chemical peeling in treatment of active acne vulgaris. An Bras Dermatol. 2017;92:212-6.

7. Gozali MV, Zhou B, Luo D: Effective treatments of atrophic acne scars. J Clin Aesthet Dermatol. 2015;8:33-40.

8. Thiboutot DM, Dréno B, Abanmi A, et.al: Practical management of acne for clinicians: An international consensus from the Global Alliance to Improve Outcomes in Acne. J Am Acad Dermatol. 2018;78(2 Suppl 1):S1-S23.e1.

9. Costa IMC, Damasceno PS, Costa MC, Gomes KGP: Review in peeling complications. J Cosmet Dermatol. 2017;16:319-26.

10. Castillo DE, Keri JE: Chemical peels in the treatment of acne: patients election and perspectives. Clin Cosmet Investig Dermatol. 2018;11:365-72.

11. Hayashi N, Akamatsu $H$, Iwatsuki $K$, et al: Japanese Dermatological Association Guidelines: Guidelines for the treatment of acne vulgaris 2017. J Dermatol. 2018;45:898-935. 